\title{
Comparative study of consultant psychiatrist and clinical psychologist among psychiatric patients, using rorschach test
}

B. Yengkokpam ${ }^{1}$, S. K. Shah', G.R. Bhantana ${ }^{1}$, P. Giri ${ }^{2}$

${ }^{1}$ Lecturer, ${ }^{2}$ Medical Officer, Department of Psychiatry, College of Medical Sciences, Bharatpur, Nepal.

\begin{abstract}
This comparative study among psychiatric patients attending College of Medical Sciences, teaching hospital, Bharatpur, Nepal was carried out to determine responses on Rorschach test (RT). A total of 65 diagnosed psychiatric patients as per international classification of diseases (ICD-10) criteria attending psychiatric OPD between ages of 15 to 65 years, both male and female in the period of January 2009 to July 2009 were selected. RT was administered and results were tabulated as per diagnosis by clinical psychologist. Out of total 65 patients who underwent RT, 41 were male and 24 were female in the ratio of 63:37. In clinical psychologist diagnosis- 38 were schizophrenia, 7 were psychotic depression, 6 were depression, 3 were mania, 1 was organic psychosis and 10 were underlying psychosis and in consultant psychiatrist diagnosis- 36 were schizophrenia, 5 were psychotic depression, 12 were depression, 8 were mania, 3 were organic psychosis, 1 was underlying psychosis.
\end{abstract}

Key words: Rorschach test, international classification of diseases, psychotic depression, organic psychosis, underlying psychosis.

\section{Introduction}

The RT was made available for use in 1920 when it was published along with the manual named psychodiagnostic. ${ }^{1}$ Test consists of ten page-sized inkblots that represent the stimulus plates of the technique. Number of surveys has been conducted in the USA, India and other countries to find out the psychological test to be highly accepted and widely used by the clinicians ${ }^{2}$ among the entire test the RT has always been found to have first place in USA, India and other countries. ${ }^{3}$

The interpretation of Rorschach protocol in most of the symptoms is based on the number of responses given by the subjects. The test has psychometric qualities and is useful for personality assessment. It has also been used in many countries. In India extensive work has been done at Central Institute of Psychiatry, Ranchi. ${ }^{4}$ Indian researchers have carried out normative studies on Indian subjects. The norms, in the form of the Rorschach indices, established by different Indian researchers have been followed.

In clinical setup, the RT is frequently and even regularly administered to resolve the diagnosis. These diagnostic indicators are generally called for the following major psychiatric illnesses or conditions: Schizophrenia, psychosis, depression, hypomania, anxiety, obsession and organicity.

Apart from these psychiatric categories, many a times, the RT is advised to understand and study the personality structure of an individual or patient. ${ }^{5}$ Patients 
are diagnosed as per ICD-10 classification of mental and behavioral disorders by a consultant psychiatrist. ${ }^{6}$

\section{Materials and methods}

All the cases in this study have been selected from psychiatry outpatient department of College of Medical Sciences, teaching hospital, Bharatpur, Nepal, between January to July 2009. A total of 65 diagnosed psychiatric patients as per ICD-10 criteria by a consultant psychiatrist between the ages of 15 to 65 years, both male and female were selected. Patients were analyzed according to age, sex and symptoms. RT was administered by clinical psychologist and results were tabulated as per diagnosis.

\section{Statistical analysis}

In the present research study obtained data have been scored by using standard scoring procedure of the tests. Chi-square test has been computed to evaluate the difference between clinical psychologist and consultant psychiatrist.

\section{Results}

Table- 1 shows that out of total 65 patients, who underwent RT, 41 were males and 24 were females in the ratio of 63:37, their age ranged from 15 to 65 years but they are divided into three age groups of 15 to 30 , 31 to 46,47 to 65 years. In the first age group from 15 to 30 years, 42 cases in which 28 were males and 14 were females, in the second age group 31 to 46 years, 20 cases in which 13 were males and 7 were females and in the third age group of 47 to 65 years and all the 3 cases of them were females. In Table- 2 comparison between clinical psychologist and consultant psychiatrist, symptom wise distribution: Clinical psychologist diagnosis: A 38 were schizophrenia, 7 were psychotic depression, 6 were depression, 3 were mania, 1 was organic psychosis and 10 were underlying psychosis. Consultant psychiatrist diagnosis: A36 were schizophrenia, 5 were psychotic depression, 12 were depression, 8 were mania, 3 were organic psychosis and 1 was underlying psychosis. The difference between clinical psychologist

Table-1: Age group of patients included in the study

\begin{tabular}{lllllll}
\hline Ages & Male & $\mathbf{\%}$ & Female & \% & Total & \% \\
\hline $15-30$ & 28 & 43 & 14 & 21.5 & 42 & 64.5 \\
$31-46$ & 13 & 20 & 7 & 10.5 & 20 & 30.5 \\
$47-65$ & 0 & 0 & 3 & 5.0 & 3 & 5.0 \\
TOTAL & $\mathbf{4 1}$ & $\mathbf{6 3}$ & $\mathbf{2 4}$ & $\mathbf{3 7}$ & $\mathbf{6 5}$ & $\mathbf{1 0 0}$ \\
\hline
\end{tabular}

Table- 2: Clinical psychologist diagnosis and consultant psychiatrist diagnosis

\begin{tabular}{llllll}
\hline \multicolumn{1}{c}{ DiagnosisSymptoms } & $\begin{array}{l}\text { Clinical } \\
\text { psychologist }\end{array}$ & $\begin{array}{l}\text { Consultant } \\
\text { psychiatrist }\end{array}$ & $\begin{array}{l}\text { df } \\
\text { (degrees of } \\
\text { freedom) }\end{array}$ & $\begin{array}{l}\boldsymbol{\chi}^{2} \\
\text { (Chi } \\
\text { square) }\end{array}$ & $\begin{array}{l}\text { Level of } \\
\text { significance }\end{array}$ \\
\hline Schizophrenia & $38(55.5 \%)$ & $36(55 \%)$ & & & \\
Psychotic depression & $7(10.5 \%)$ & $5(7.5 \%)$ & & & \\
Depression & $6(10 \%)$ & $12(18.5 \%)$ & 5 & 29.11 & 0.01 \\
Mania & $3(5 \%)$ & $8(12.5 \%)$ & & & \\
Organic psychosis & $1(1.5 \%)$ & $3(5 \%)$ & & & \\
Underlying psychosis & $10(14.5 \%)$ & $1(1.5 \%)$ & & & \\
Total & $\mathbf{6 5}$ & $\mathbf{6 5}$ & & & \\
\hline
\end{tabular}


and consultant psychiatrist was found to be statistically significant at 0.01 levels $\left(\mathrm{x}^{2}=29.11, \mathrm{P}<0.01\right)$.

\section{Discussion}

Psychiatric diagnoses were based on ICD-10 criteria. Recent research has revealed that norms cannot be used from one country to another and differences within the same cultural group are also to be found. ${ }^{7,8}$

The Rorschach norms were established by researchers in India differ considerably. ${ }^{9}$ Most of these studies had a number of shortcomings the most important being the relatively small sample size from one center, which was not representative of the service. In the absence of reliable norms, mental health professionals in India are left with no alternative but to interpret. Our aim in this study was to divide the patients in subgroups based on the age, sex and symptoms wise distribution. General background information and behavioral data that are generally considered to be of importance in finding symptoms could be illuminating for this purpose. Differences in terms of such additional data would support the meaningfulness and validity of the suggested sub groupings.

Our results suggest that these patients display a rather complex pattern of psychological functioning, with emotional encumbrance and also a more complex psychological relation to symptoms itself. Although psychological resources were higher in this group, there were also more psychological factors possibly counteracting. Out of the sample of total 65 patients, who underwent RT, 41 were males and 24 were females in the ratio of 63:37. There are differences between Clinical psychologist diagnosis and Consultant psychiatrist diagnosis as shown in table-2. In Clinical psychologist diagnosis 38 were schizophrenia, 7 were psychotic depression, 6 were depression, 3 were mania, 1 was organic psychosis and 10 were underlying psychosis. But in Consultant psychiatrist diagnosis: A 36 were schizophrenia, 5 were psychotic depression, 12 were depression, 8 were mania, 3 were organic psychosis and 1 was underlying psychosis. The results of this study indicate that there were clinically meaningful in the diagnosis of a psychiatric disorder.

Acute schizophrenics are quick and impulsive as the normal inhibition is lifted in them. This trend is in agreement with some studies though one study observed longer RT in schizophrenics which may be attributed to differences in the sample characteristics. A chronic schizophrenic is likely to have a longer RT as compared to an acute schizophrenic. The RT of head injury and epilepsy patients was significantly more than the RT of the psychotic subjects, which is in agreement. In this study, we investigate the reliability, and diagnostic efficiency of the RT in relation to the accurate identification of patients diagnosed with ICD10 criteria, schizophrenia or other psychotic disorder. Finally, this variable could be employed for classification purposes in ways that were clinically meaningful in the diagnosis of a Psychotic disorder. Conceptual and methodological issues are discussed in relation to the assessment of psychosis. ${ }^{10}$

Ilonen et al. reported out of twenty-seven patients with first-episode schizophrenia, 13 with bipolar I disorder, 28 with psychotic depression, 29 with nonpsychotic depression, and 60 healthy controls were recruited for the study. The schizophrenic was highly specific with a very low false positive rate. The lowest positive value of 4 , however, may yield false positives, especially among manic patients. The depressive disorder patients identified severe non-psychotic depression but not psychotic depression, suggesting that these patient groups invoke different perceptual- 
B. Yengkokpam et al. Comparative study of consultant psychiatrist and clinical using rorschach test

cognitive processes in formulating and articulating their Rorschach responses. Anyway, both the schizophrenic and the depressive disorder patients based on the psychological organization and functioning that are known to play a clearly formulated role in schizophrenia and depression, respectively, provide a valuable addition for diagnostics characterized by overt symptoms. ${ }^{11}$

Finally, it is important to consider that this research opens an area of interest for the study of human behavior in the definition of conduct. The present findings although preliminary, shed some light into this matter. Furthermore, these results are concordant with diagnostic and semiologic instruments such are those suggested by Kandel ${ }^{12}$ and Kaplan ${ }^{13}$, among others. In the genesis of these clinical conditions we must consider genetic factors as well as environmental issues such as parental relations, social stressors, workrelated stressors, familiar stressors. ${ }^{14}$

\section{References}

1. Rorschach H. Rorschach psychodiagnostik. Ernst Bircher, Bern 1921:12.

2. Dubey BL. Rorschach analysis of importance cases and their response to psychotherapy. Indian J Clin Psychol 1977; $4: 145-9$.

3. Fiske DW, Baughman EE. Relationship between Rorschach scoring categories and total number of responses. J.Abnor Soc Psychol 1953; 48: 25-32.

4. Shukla TR. Psychodiagnostic efficacy of Holtzman inkblot technique under Indian condition- a normative study. Indian J Clin Psychol 1976; 3: 189-98.
5. Asthana HS. Some aspects of personality structuring in Indian social organization. J Soc Psychol 1956; 44:155-63.

6. WHO. ICD-10 classification of mental and behavioral disorders 2002.

7. Nascimento RSGF. The impact of education and /or socioeconomic conditions on Rorschach data in a Brazillian non patient sample. Rorschiana 2004; 26 : 45-62.

8. Singh DK, Singh A, Singh AR. Relevance of Beck norms of Rorschach inkblot technique on Indian populationan exploratory pilot study on normal subjects. SIS J Projective Psychol Mental Health 2004; 12: 49-52.

9. Manickam LSS, Dubey BL. Rorschach inkblot test in India, Historical review and perspectives for future action. SIS J Projective Psychol Mental Health 2004; 12: $61-78$.

10. Hilsenroth M J, FowlerJC, Justin RP. An examination of reliability, validity and diagnostic efficiency. Rorschach Schizophrenia Index 2006; 86: 180-9.

11. Ilonen T, Taiminen T, Karlsson H, et al. Diagnostic efficiency of the Rorschach schizophrenia and depression indices in identifying first-episode schizophrenia and severe depression. Psychiatr Res 1999; 87: 183-92.

12. Kandel ES. Neurociencias y conducta. Prentice Hall 1997: $75-81$

13. Kaplan HI, Sadock BJ. Tratado de Psiquiatria Tomo I. Ed Intermedica 1997: 92-3.

14. Nilson M, Perfilieva E. Enriched environment increases neurogenesis and improves spatial memory. J Neurobiol 1999; 39: 569-78. 